\title{
A SENSEMAKING STUDY OF CHANGE INITIATIVE: THE CASE OF A MALAYSIAN MULTINATIONAL ENTERPRISE
}

\author{
NIZAM ABDULLAH* \\ MOHD NAZARI ISMAIL \\ Department of Policy and Business Strategy, University of Malaya, Kuala Lumpur, \\ Malaysia. \\ *Corresponding Author: nizamaa@gmail.com
}

\begin{abstract}
Empirical evidence has emphasised the need for more research to uncover why does change fail and what can organisations do to improve their success rate. The purpose of this article is to provide an in-depth assessment on the implementation of centre-led change initiative in a novel empirical study in a Malaysia-based multinational enterprise (MNE). This study is based on a multiple embedded case study of four subsidiaries of a Malaysian-based MNE. This study urges centre managers tasked with implementing strategic change initiatives to emphasise the behavioural aspect of those involved in change throughout the entire development stage of the change. Any negative cues from change recipients need to be addressed and attended to as quickly as possible. This study is based on a section within the larger context of the MNE being studied. The study contributes to the literature of organisational sensemaking in change by extending the knowledge of new sensemaking forms namely communication intensity and resolution to barriers. This study also contributes to the empirical literature on change by providing an in-depth account of a Malaysia based MNE journey in implementing centre-led change initiatives.
\end{abstract}

Keywords: Sensemaking, Multinational enterprise (MNE), Organisational change, Middle manager, Case study.

Received: 26/7/2018

Revised: 04/11/2018

Accepted: 23/12/2018

Published: 14/7/2019

\section{Introduction}

Within a decade, studies on middle management has gained a strong momentum ever since the 1980s and 1990s (Kanter, 1982, Floyd \& Wooldridge, 1992). This short span of time shows a growing number of scholars have acknowledged that middle managers are considered to be critical key agents in determining organisational strategic direction and hence, organisation change. The development of studies about multinational companies in the past 30 years was another turning point that contributed to the growing number of scholars converging into the study of middle managers from the past. The previously understood hierarchical nature of MNE has since evolved into what scholars term as heterarchy (Hedlund, 1986) or differentiated network (Nohria \& Ghoshal, 1997). What this entails is that research on subsidiary management has progressed steadily from HQ-subsidiary relationship (Brandt \& Hulbert, 1977, Hedlund, 
1980), subsidiary role (Bartlett \& Ghoshal, 1986, White \& Poynter, 1984), subsidiary evolution (Zander \& Kogut, 1995, Malnight, 1996) to subsidiary managers (Reynolds, 2015, Balogun et al., 2015).

Within the study of sensemaking, there are two dominant streams within this field. First is the literature on sensemaking and crisis (Brown \& Humphreys, 2003, Gephart, 1997) and the other is sensemaking in change (Balogun, 2006, Balogun \& Johnson, 2005, Balogun et al., 2015). While there is a strong stream looking into sensemaking and crisis, the focus of this paper is on the latter that is within organisational change. The aim of this paper is to explore the phenomenon where key managers (middle managers), are faced with competing roles during the implementation of centre-led change initiative. Middle managers are position in a unique position between carrying out strategic direction set by top management and leading the employees to implement those direction. They have within their span of resources the power to act convergently or divergently towards imposed direction such as change. The study draws from several organisational sensemaking/sensegiving theory (Maitlis, 2005, Maitlis \& Lawrence, 2007), middle management literature (Rouleau and Balogun, 2011, Teulier and Rouleau, 2013), and literature on power and politics (Geppert et al., 2016, Conroy et al., 2017).

Various studies have been done in established MNEs such as Toyota (Dohse et al., 1985), ABB (Belanger, 1999) and General Electric Company (Ocasio \& Joseph, 2008). However, many of the research has paid little attention to the Asia or Asia Pacific region. Much of the business and management research are dominated by Western evidence and context without adequate attention on the influence of local or regional settings such as the 'Asian values' (Rowley, 2017). Multinationals operating in the Asian region have to continually contend to adopting a global mind set while at the same time not ignoring being there as 'locals' (Asma, 1996). It is becoming increasingly difficult in ignoring to understand how firms' organisational learning develops in a multicultural environment such as in the Asian region.

The study is designed as a multiple embedded case study (Yin, 2003). It is conducted in a Malaysia based MNE (CenCo), where a centre-led change initiative, the Central Electronic Management System (CEMS) was studied over a period of four years between 2013 and 2016. Real-time, longitudinal data were gathered across four subsidiaries in four different countries namely Malaysia, Bangladesh, Indonesia and Sri Lanka. The purpose of this article is to understand, from the perspective of key managers involved, how a Malaysian multinational company implements strategic change initiatives across several of its subsidiaries within Asia from the perspective of those involved.

This article contributes to current literature on organisational sensemaking by providing insight into rich qualitative accounts from informants involved in political behaviours in change. Such studies are considered to be rare (Birkinshaw et al., 2011), they provide a glimpse of what transpired within the organisation, "how" and "why" certain actors act the way they do in certain change. This enhances our understanding within the corridor of power and organisational politics. This study extends further the organisational sensemaking literature by providing evidence of the struggle key actors go through changes in the form of sensegiving activities. Finally, this article provides a supplement to the change literature by providing an insight on why change fails and what can organisations do to improve the success rate of change (Burnes, 2011).

\section{Organisational Change and Sensemaking}

Organisational members such as leaders, middle managers and stakeholders engage in 
sensemaking such as in environmental scanning that influences decision making and strategic change (Gioia \& Thomas, 1996). Maitlis explains that in organisational sensemaking, members scan their environment through their interactions with others, 'constructing accounts that allow them to comprehend the world and act collectively' (2005: 21). Thus, sensemaking helps organisational members deal with ambiguity and uncertainty such as that found in change, by creating a sense of the environment which then enables action.

\section{Sensemaking in Change}

Individuals tend to behave in a routine state of "trance", when the organisation is in a state of stability. However, when change is introduced, individuals' routines are interrupted and they would and should be more alert to their surroundings. They interact with others in making sense of what is going on around and figure out methods to respond (Weick, 1995). Individuals engage in conversations, exchanging gossip, stories, rumours, and memories about past experience. They take note of symbolic actions \& behaviours (Isabella, 1990, Gioia \& Chittipeddi, 1991, Humphreys \& Brown, 2002). Through these social processes, organisational

In the general literature, there exists a steady growth of research in micro processes that underlie organisational change (e.g. Balogun et al., 2015, Balogun et al., 2011, Giuliani, 2016). Hence, the obvious focus on the sensemaking activities is on the actors involved in strategic change processes. These individuals have a profound influence on how others adapt the meaning of change and how they react to change. Eventually, this then affects how the overall organisation adapts to those changes. One critical factor that needs to be considered is the type of sensemaking activity that should be examined. In organisational change, the various organisational members such as the top management (e.g. Gioia \& Chittipeddi, 1991), middle managers (e.g. Balogun and Johnson, 2004) and other stakeholders (e.g. Maitlis, 2005), all play important roles in shaping the meaning of change.

To date, there has been studies that show how centre-led change initiatives, have been implemented with elements from both external and internal, and are contingent to the emergence of subsidiary managers' autonomy and their capability to do otherwise (Birkinshaw et al., 2005, Bouquet \& Birkinshaw, 2008a, Bouquet \& Birkinshaw, 2008b, Birkinshaw \& Pedersen, 2009). Birkinshaw et al. (2011) consider qualitative research with rich detailed accounts from the inside as something unique in the international business literature. They encourage researchers to adopt a more "upclose and grounded" approach. Hence, it is the aim of this study to fill this gap by providing the understanding how the implementation of centre-led change initiatives is affected by the different patterns of interaction between centre and subsidiary managers. This approach requires a qualitative research to be implemented. Thus, the formulation of this study's research questions is outlined as:

1) What are the patterns of interaction enacted by centre and subsidiary managers involved in centre-led change initiatives?

2) How do these patterns of interaction influence the development of centre-led change initiatives?

3) What are the implications of these patterns of interaction towards the outcome of the centre-led change initiatives?

\section{Research Methods}

A researcher with a constructivist views often looks at the processes of interaction among individuals when studying on the organisation. This view considers organisation as a socially constructed entity (Creswell, 2009). Bartlett 
and Ghosal (2002) explain how the transnational company have adopted to varying forces both internally and externally. Organisational change is essentially constant in today's MNEs.

The primary aim of this research is to examine how centre-led change initiatives are implemented in a Malaysia based MNE across its subsidiaries in Asia from the perspective of those involved. What is missing in the general international business research are detailed studies of how certain processes unfolds such as strategic change, taking into account the different interaction between managers involved (Dorrenbacher \& Geppert, 2006). The research to date has tended to approach mostly from outside the company rather than from inside which may be due to the issue of access. Hence, this is best approached through an exploratory qualitative study from inside the company.

\section{Research Design and Data Source}

CenCo, one of the largest telecom operators in Asean and South Asia with approximately 350 million customers was identified as the case for this study. CenCo is an MNE headquartered in Kuala Lumpur, Malaysia with several subsidiaries in different parts of Asia, namely Malaysia, Sri Lanka, Bangladesh, Indonesia, India, Singapore and Cambodia. Access to CenCo was secured through the rapport established almost a decade ago by one of the authors, who had worked in one of the subsidiaries.

Four subsidiaries were identified (CenCo's shareholding): 1) MyCo (100\%) of Malaysia; 2) $\mathrm{LaCo}(85 \%)$ of Sri Lanka; 3) BaCo (70\%) of Bangladesh; and 4) InCo (66.7\%) of Indonesia. Figure 1 depicts the geographical, shareholding and relative information of subsidiaries within the CenCo group. They were chosen due to their high-performance status and their significant contribution to CenCo in terms of monetary profits. This is important as it presents a case where subsidiaries with relatively "high power and voice" may not necessarily conform to what the centre wishes them to do that serve as the central issue to this study (Mudambi et al., 2014).

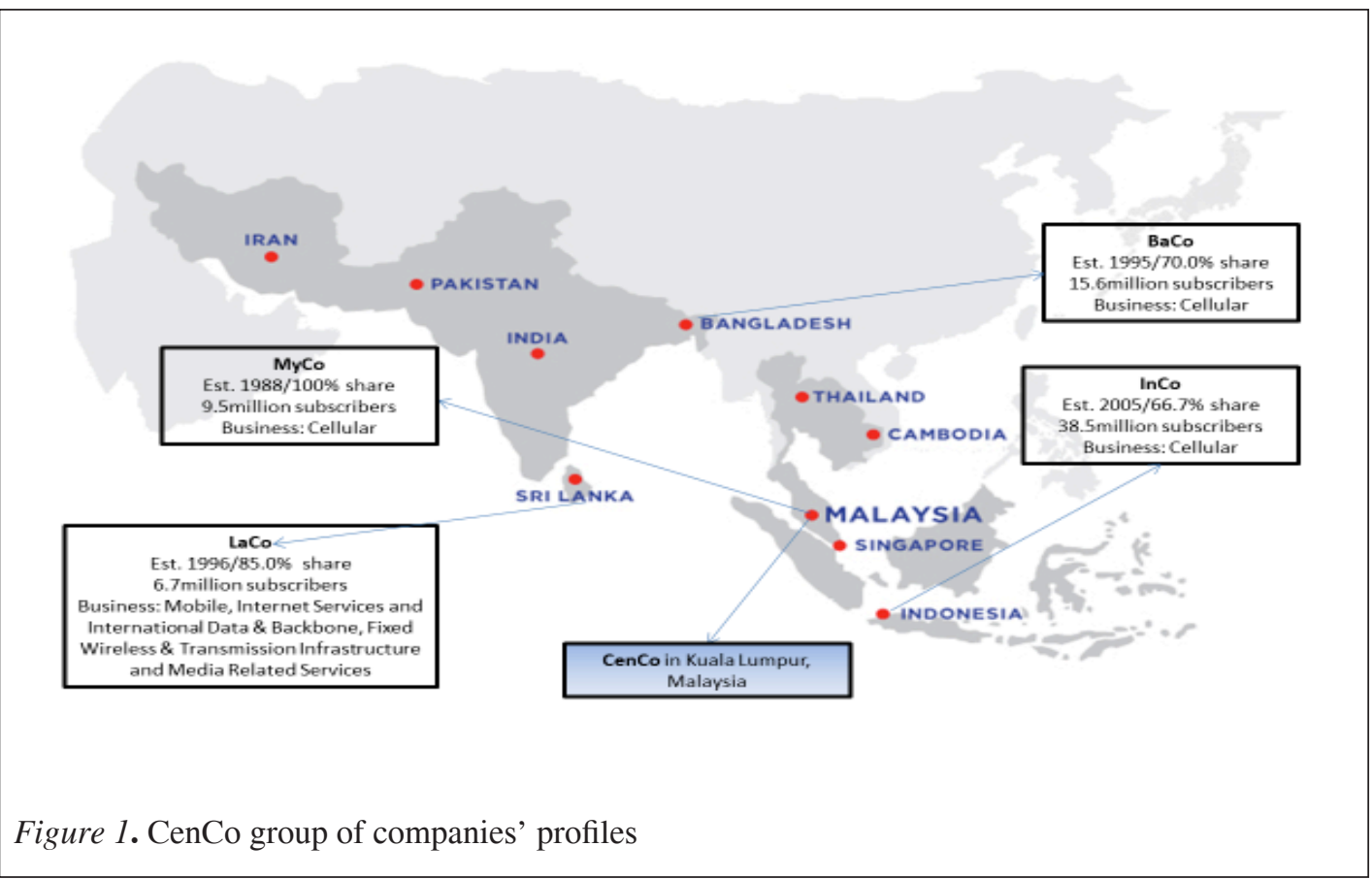


The change initiative was chosen based on three criteria. First, the initiative must be within the past three years as individuals find it difficult to articulate contexts which they have become detached from. Second, the initiative must be significant such as those that require changes in major processes, realignment or system upgrade. Third, the initiatives must be initiated from the centre and intended to be implemented across all subsidiaries. Following this, the Central Electronic Management System (CEMS) initiative was identified. The CEMS, is an electronic work program designed as an electronic reporting tool. Among the expected benefits of implementing CEMS are structured entity's risk assessment, electronic work papers, paperless environment, maintain systematic and standardised process flow, controlled process and audit coverage, ease of sign-off and review of each task and work papers, dashboard for snapshot, ease tracking of work progress, reports and issues, and accessible anywhere and time flexibility (via web).

Amid the established rapport mentioned earlier, a letter was written to the Chief Executive Office of CenCo in Kuala Lumpur, Malaysia via e-mail. An endorsement was then requested from the Chief Human Capital Officer of CenCo to conduct the study. Following the positive responses of the managers, a preliminary interview was followed with informants at each of the subsidiaries and the centre. This allows the authors to appreciate the context surrounding the CEMS initiative while at the same time building the list of potential interviewees in each entity. A critical events chart was developed surrounding the CEMS initiative starting from 2013 to 2015 (Isabella, 1990).

Data collection started with the collection of archival materials comprised of internal documents, bid submission document by seven vendors, board papers, internal and external communications, brochures, certification documents, and other relevant reports. Finally, an approximate of 8,000 pages of document were uploaded into NVivo10 for data management purposes.

An interview protocol based on a semistructured technique was developed to provide a form of guidance throughout the data gathering stage (Kvale \& Brinkmann, 2009). Three simple questions were posed: (1) Tell me about yourself? How did you get here to doing this job? (2) One of the things that I am particularly interested is on the subject of how strategic initiative unfolds. I need you to share about the history of the CEMS initiative? (3) Who else you think might help me in this matter that we have discussed? The three questions presented above seems basic in nature. However, in the actual interviews, the author had to steer the interviews many times so as to ensure the focus of the topic at hand. The nature of the open-ended questions allow freedom for the interviewees to express matters pertaining to their unique experience and within their own meaning of the constructs. The language used by the informants was sometimes interchangeable in the informants' native language. However, this was very minimal, as the confirmation of the meaning was done almost immediately.

The saturation level in qualitative technique such as the interview is considered to be somewhere in the range of 10 and 30 (Campbell \& Stanley, 1963). For this study, a total of 22 semi-structured interviews were conducted between March 2014 and May 2016 with key actors involved in the initiative within four different countries spanning across Asia. The interviewees included one senior vice president at the centre, four vice presidents from several subsidiaries, an assistant vice president of the centre and the remaining are employees of the subsidiaries. Table 1 lists the interviewees and their profiles. Each interview lasted between 20 to 100 minutes per session. All interviews were tape recorded except for two hours in which case they were hand written and transcribed immediately after the interview. The transcription process was assisted by two professional transcribers. Special care was taken 
to brief the transcribers on some regular term use by interviewees such as for BaCo, the term "Bhai" is often used referring to an elderly person or as a sign of respect. Other words such as OpCos, refers to Operating Companies and "EBiz" refers to the business intelligence module. Apart from the regular use of special terms, the majority of the interviewees' accent was from Bangladesh and Sri Lanka had posed some difficulty for the transcribers in some cases. In addition to the face-to-face interviews, one of the authors was also granted permission to attend some of the meetings such as the divisional meeting as an observer. Field notes from the observation were made to capture events such as site meetings, discussion and internal briefings.

Table 1

Interviewee Profiles

Centre and subsidiary staffs interviewed

(1) Senior Vice President Centre

(2) Vice President 1 Subsidiary

(3) Vice President 2 Subsidiary

(4) Vice President 3 Subsidiary

(5) Vice President 4 Subsidiary

(6) Assistant Vice President 1 Centre

(7) Assistant Vice President 2 Centre

(8) General Manager 1 Subsidiary

(9) General Manager 2 Subsidiary

(10) General Manager 3 Subsidiary

(11) General Manager 4 Subsidiary

(12) General Manager 5 Subsidiary

(13) Senior Manager 1 Subsidiary
(CXO) The group head of department (HOD), he was formerly a finance director of an oil and gas MNE based in Kuala Lumpur. He reports directly to the Group's Board. All local boards' report to the Group's Board.

(M1) The head of department (Bangladesh), he reports directly to the local board with an indirect reporting line to the centre. He was hired based on his wide MNE experience in the tobacco industry.

(M2) The head of department (Indonesia), he reports directly to the local board with an indirect reporting to the centre. His experience in the telecom industry was primarily for his hiring.

(M3) The head of department (Sri Lanka), he reports directly to the local board with an indirect reporting line to the centre. An Oxford graduate (OXON), his previous experience in a similar role was the primary reason for his hiring.

(M4) The head of department (Malaysia), he reports directly to the Centre. A long-time employee of $\mathrm{MyCo}$, he rose through the ranks to his current post. He is perceived to be the successor to the SVP at the Centre.

(CM1) The head of department, she is in charge the financial aspect of the department. An accountant by profession, she has various certifications under her portfolio.

(CM2) A senior lead specialist in the department. He specialises in project management and general management. He reports directly to the Centre's head of department.

(SM1) A senior specialist in general management, he reports directly to the HOD (Bangladesh) and in charge of the general management of the subsidiary.

(SM2) A specialist in marketing, he reports directly to the HOD (Bangladesh). He has a pool of staffs under him.

(SM3) An IT specialist, he reports directly to the HOD (Bangladesh). He was formerly a local bank's technical manager for IT related works. A pool of team reports to him.

(SM4) An engineer by profession, he reports directly to the HOD (Bangladesh). He joined the company a fresh graduate and rose to the current position

(SM5) A marketing specialist with several regional postings across Bangladesh, he reports directly to the HOD.

(MS1) A qualified accountant, he reports directly to the HOD (Sri Lanka). He is the delegation of authority (DOA) when the HOD is out of the country. 
Centre and subsidiary staffs interviewed

(14) Senior Manager (MS2) 2 Subsidiary

(15) Manager 1 Subsidiary

(16) Manager 2 Subsidiary

(17 Manager 3 Subsidiary

(18) Manager 3 Subsidiary

(19) Manager 4 Subsidiary

(20) Assistant Manager 1 Subsidiary

(21) Assistant Manager 2 Subsidiary

(22) Assistant Manager 3 Subsidiary
An accountant by profession and an IT certified assessor. He was formerly a manager in Qatar and was hired to head the IT unit of the department. He reports to the GM of IT (Malaysia).

(ES1) An IT specialist, he reports directly to the HOD (Indonesia). He was formerly the IT development and operations (devops) team of the subsidiary. He is assigned specifically as the subsidiary system administrator.

(ES2) An accountant by profession, she reports directly to the HOD (Indonesia). She has a wide span of experience in the subsidiary.

(ES3) An accountant by profession, he reports directly to the HOD (Sri Lanka). His previous experience at a local bank and knowledge in IT were the primary reasons for his hiring.

(ES3) An engineer by profession, he reports directly to the HOD (Malaysia). He is among the most senior within the subsidiary.

(ES4) She is the IT specialist and reports directly to the HOD (Malaysia). She has a pool of team that reports to her directly.

(AM1) An accountant by profession, he reports directly to the DOA (Sri Lanka).

(AM2) An IT graduate and in charge of IT related tasks. He reports directly to the IT Manager (Indonesia)

(AM3) A computer science degree holder, he reports directly to the HOD (Sri Lanka). He oversees all general management related issues within the department.

\section{Data Analysis}

Data analysis was performed simultaneously with data collection as recommended by Miles and Huberman (1994). The data was examined across various informants, level and sources. This facilitates in forming a kind of data validity for qualitative study (Saunders et al., 2009:142143). It is also sometimes refers to as a form of triangulation. A two-order analysis (Gioia \& Chittipeddi, 1991) was performed on the data set. The first order analysis is performed in searching for themes and patterns that included and perceived to be meaningful that has been used by interviewees in the research. The second order is a more theoretical analysis level where data and the first order analysis outcome were examined for underlying meanings.

Table 2 depicts the steps for data analysis in the study. The author analysed the change initiative and identified more than 40 issues. Three sets of criteria were used to filter the issues. Firstly, the issue must be present in all subsidiaries. Secondly, the issues must be available from multiple sources as oppose to only one interview. The third and last criterion is that the informants must consider an issue of real significance. A final 12 issues were identified where these arise between centre and subsidiary managers. All the 12 issues were confirmed with the informants. For each of the issue, the author builds narratives from the interviews, field notes, meetings, reports and other secondary sources.

The second stage of the data analysis is identifying the forms of sensemaking. It is broken into three smaller parts, namely analysing center manager sensegiving, analysing subsidiary manager sensegiving and identifying process characteristics of organisational sensemaking. In this step, the author confirms that all individuals were involved in most of the key issues identified earlier. Next, the author identifies a 
list of centre managers' sensegiving activities. Following this, the sensegiving activities are matched to the key issues identified. Next the author identifies the frequency and intensity of the sensegiving activities. Next the authors grouped the 12 issues into three categories of centre, subsidiary and internal sensegiving roles. Each of the centre-subsidiary, subsidiarysubsidiary and subsidiary-internal interaction for each form was then reviewed. Next, the author reviews each sensemaking process to determine their characteristic for each form.
An iterative analysis was done to build a more abstract process descriptor. The activities in this stage help to ensure robust descriptors for each organisational sensemaking form.

The final stageinvolvesidentifying commonalities in each account associated with each form and performing iterative analysis, building a more abstract description of the sensemaking. The final stage helps to ensure a robust process outcome of each organisational sensemaking form.

Table 2

Data Analysis Steps

\begin{tabular}{|c|c|c|}
\hline Data Analysis & Steps & Results \\
\hline $\begin{array}{l}\text { Sensemaking processes } \\
\text { involve in all the initiatives }\end{array}$ & $\begin{array}{l}\text { - All issues arise between centre and subsidiary } \\
\text { managers } \\
\text { - } \text { Filter the issues based on the set criteria } \\
\text { - } \text { Building narratives based on the key issues } \\
\text { from the interviews, field notes, meetings, } \\
\text { reports and other secondary sources }\end{array}$ & $\begin{array}{l}\text { 1. Funding of the system } \\
\text { 2. Awareness and training } \\
\text { 3. Subject matter expert } \\
\text { 4. Data sovereignty } \\
\text { 5. Accessibility } \\
\text { 6. Data security } \\
\text { 7. Complexity of process and } \\
\text { 8. Lack of support } \\
\text { 9. Lack of direction } \\
\text { 10. Rush through } \\
\text { 11. Objective not met } \\
\text { 12. Differentiated treatment }\end{array}$ \\
\hline
\end{tabular}

Identifying forms of sensemaking based on:

- Analysing centre manager sensegiving

- Analysing subsidiary manager sensegiving
- Confirm that all individuals were involved in most of the key issues identified earlier.

- Identifying a list of centre, manager sensegiving activities.
Robust descriptors for each organisational sensemaking form. 


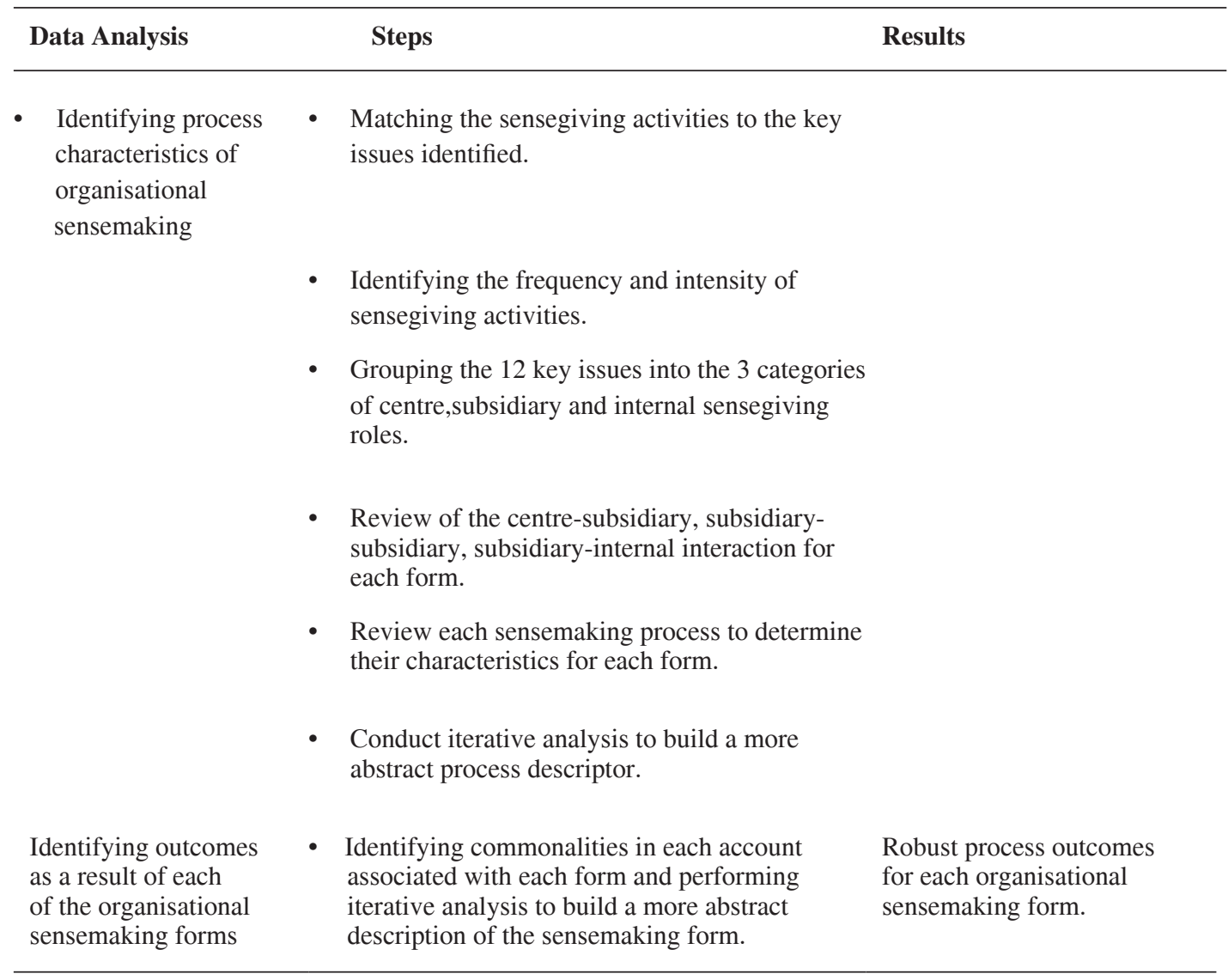

\section{Findings}

Firstly, an illustration was made on several actors or individuals interact to shape the meaning of change through their communication and meaning construction. This is traced through CEMS' two stage implementations. The first stage is called CEMS development, which comprises of the planning and implementation activities. The following stage is referred as to the business-as-usual (BAU) this is also known as the steady state. The findings extend as follows.

\section{Planning/Implementation Phase}

Sensemaking/sensegiving - CenCo and subsidiary: CenCo introduced the CEMS initiative after they obtained the Board's approval in the late 2012. This was followed with the sourcing of a solution provider from several vendors, CenCo finally decided in the early 2013 to appoint a UK based vendor. A CEMS awareness session was held at the regional meeting (hereinafter $\mathrm{RM}$ ) in Kuala Lumpur. CEMS' objectives were deliberate, and high-level discussion was exchanged by participants that consist of all subsidiary managers. CenCo's manager (CXO) outlines that the CEMS initiative is the right move for them as a multinational:

Our overall idea is that we are hoping as a multinational company, how do multinational company managed to exist for many, many years. It is not because they have a set of separate 
people or because they try to get the best people, it's because of their system - they have a strong system and process.

The CXO informed all subsidiary managers that CEMS was approved by the central Board, thus need to be implemented. While subsidiary managers describe that the CXO's approach at the early stage was engaging, but there were times it intertwined with being perceived as persuasive. Subsidiaries were consistently being reminded of the Board's mandate of the CEMS initiative. What follows several RMs later is that discussions went deeper as the objective, timeline and cost implications were discussed. From the four subsidiary managers, M2 was quite critical of the CEMS initiative, he explained:

What the group wants to do is very good. It is like centralising everything but at my side, although we see it as a good initiative, but there was some constraint on our side. There are two constraints; one is the technical capabilities of having a centralised database application or maybe that's the key one. Which we have tested, but in our view was inefficient at that time. Perhaps it was effective as far as knowledge management is concerned. But it was completely inefficient to have it centralised due to technical capabilities.

M2 expressed concerned that CEMS will not be able to function effectively due to the centralised database located in Kuala Lumpur.

The CEMS trial period for each subsidiary depending on the installation was between 6 and 9 months. However, at the end of the trial period, none of the subsidiaries were using CEMS as expected by the CXO. What happens next was that the CXO made it mandatory that CEMS' implementation status update and usage were a permanent RM agenda. Subsidiary managers recalled that there was an air of tension being pushed to them by CenCo. M2 recalled, '[...] there was also case of pressure for the centre-led initiative to be completed according to target. And this target is being monitored by the Board anyway'.

In several RMs later, disagreements on cost and data confidentiality were highlighted by M1 and M2 respectively. M3 on the other hand raised issues about remote accessibility and stability of CEMS. CXO responded partly in that, all license fees of CEMS shall be at no cost to subsidiaries, while data confidentiality was assured by the CenCo's data centre team. M3 recalled what the CXO said to them, "you can use this system for free". Essentially the licensing fee and the software all borne by the CenCo.

M2 on the hand was still troubled by the issue on data security, he reiterated several times that their country regulation requires all the company's data must reside within the country it operates. This is contrary to how the CEMS system operates, where all data are centrally located in Malaysia. M2 explained:

In fact, there are two things about this information. First, the issue of sharing, the second is about where the data are kept. But I thought at that time the concern was about having the data visible to one up to the major shareholders when there are also other shareholders [..] The other part is the regulations required information about the company to be stored within the country. There is a regulation on that, but I cannot recall specifically which regulation that was but on the previous one there is. 
Although M2 incessantly explained that the CEMS system is not operating according to Indonesian law, but it was to no avail. He summed up the attitude of CXO, "so it's like use or explain, kind of attitude" (M2). The confrontation between $\mathrm{M} 2$ and $\mathrm{CXO}$ prolonged until it eventually led to InCo opting out from the CEMS initiative at the planning stage. This process where M2 successfully managed to opt out from CEMS centre-led initiative was a complex round of discussions that involve the InCo's regulatory team and one local board committee member. M2 recalled that his board member was concerned "with regard to data protection, data security, questions like who will have access to [the] data".

\section{Sensemaking/sensegiving - internal subsidiary:} Subsidiary managers held their own divisional monthly meetings attended by their respective staffs. In subsidiary divisional meetings, they held various agendas that include corporate communications and sustainability issues, dayto-day operational issues and updates from the centre. In mid-2013, at the divisional meeting, subsidiary managers began to introduce the CEMS concept to their respective team members.

The centre relied on the CEMS vendor to rollout the system across the four subsidiaries. As MyCo is located in Kuala Lumpur, so thus the CEMS database, the vendor planned for the first installation to be at MyCo. The process involve configuration to the virtual server, installation of licenses in each users' laptops and followed by a two-day hands-on training to all users. Next, the vendor flew to each subsidiary and replicate the same process with an additional task that is to establish a secure virtual private network access to the CEMS central database in Kuala Lumpur. The vendor provided a $24 / 7$ technical support for all subsidiaries as defined in the annual maintenance contract for the first year.

Subsidiary managers sensegive their staffs that CEMS was about an improvement in the work process. It is also for the sake of shortening reporting cycle time and virtual work. M1 and M3 went a little further, they envisioned that CEMS will eventually lead to reduce storage space, paper and eventually overall cost. Each of them led a "Go Green" campaign at their respective department. M3 recalled that "the biggest challenge was actually understanding how the system actually works". He explained further:

The biggest problems for many people, especially those who are not IT savvy is when you look at an IT interface and you see a lot of places where you can write something, where it doesn't have a drop down "Menu" to guide you what it is supposed to be there. Just a text box and those text boxes don't even have... is not even tagged with... a term that everybody is familiar with.

In contrast, the subsidiary employees that had already been burdened with a heavy daily workload consisting of fieldwork and reporting was skeptical about CEMS. Subsidiary staffs were not particularly concerned about cost saving as it does not contribute to their key performance index (KPI). MS1 recalled about CEMS,
When the system first came on, everybody was excited, you know there's a system coming out, coming in and you could do it, but then after we got to know that it is just a repository of course it came as an "added burden". This is because you know after each process, you have to do it back again, its duplication to a certain degree although I don't think it's $100 \%$ duplication.

They further felt that CEMS was the Centre's project and their managers were left with no choice but just to implement as instructed. In 
contrast to the feeling felt by the employees, the implementation phase that included the software installation, training sessions and the trial period were executed seamlessly. However, CEMS usage was low as many users were not familiar with the system.

\section{Business-As-Usual Phase}

Sensemaking/sensegiving $\quad-$ CenCo and subsidiary: In the BAU phase, CenCo sensegive to its subsidiaries that CEMS is given free of charge. CEMS also will help to elevate their status as a multinational being at the same par with other more established MNE worldwide. CEMS was further introduced as a module for new entrants to the department in the yearly kick-start orientation program. In the year ending 2013 with CEMS' successfully implemented in all its subsidiaries, CenCo achieved a KPI level-L5 (highest). However, no subsidiary at CenCo achieved the L5 KPI as their measurement differs from CenCo. They were measured based on the CEMS usage. This has caused some resentment from the subsidiaries. M1 and M3 felt that CEMS was more about a project to CenCo rather than a paradigm shift in new ways in doing work. CenCo was seen to be more concern in driving the CEMS initiative, however the detail ongoing of its implementation is rather low.

M2's moves in implementing their own CEMS system were seen by other subsidiaries to be more successful than CenCo's CEMS. M2 in his own words elaborated:

So why has the centre failed? And not in my side, in my opinion because I decided that for a major shift of paradigm and behaviour this requires dedication. So, we create our own small team, right? So, we call it the quality and the technical team that look and focuses more on this initiative of CEMS.

While MyCo and LaCo were passive than its peer subsidiary, BaCo and InCo went a little more in making efforts to make CEMS as a workable system. While InCo had the freedom to explore CEMS as a standalone system. However, it was $\mathrm{BaCo}$ that had to improvised and work within the limited in-house resource they had to try to make CEMS a successful system.

Sensemaking/sensegiving - internal subsidiary: As the number of CEMS users grew, resulting from CenCo's pressure, numerous issues relating to system, accessibility began to mount. Many felt frustrated that the CEMS system was far from its objective that was to improve the way they work as it was supposed to be about office automation.

CEMS users' sensemake that the system is a time waster and it is an added burden, unnecessary to their daily routine. They had called the "dumping data system" or "double work". MS1 mentioned,
[...] there was no interactive reporting mainly because I think of the network connectivity issue, so we were actually using it (CEMS) as a repository just to keep on reports "dumping data" after the work. There was no sort of ongoing work within the system, it just functioned as a repository.

Sensemaking/sensegiving - subsidiary and subsidiary (the Rebel Alliance): M2 and M3 related their displeasure about CenCo's disparate treatment on matters concerning set milestones and deliverables. The local subsidiary, MyCo though clearly lags other subsidiaries was less pressured. As CenCo put pressure for CEMS's 
usage, subsidiary managers began to discuss this more openly. They voiced out their dissatisfaction about the different treatment during and after the RMs, but CenCo incessantly ignored this.

During one of the face-to-face interviews, the author discovered an informal alliance among M1, M2 and M3. Through formal and informal discussions, they had formed a pact, they call themselves the 'Rebel Alliance'. M1 elaborated,

\section{[...] we had to agree among ourselves and not like having a 'rebel alliance' per se. It is just the three of us. We were brainstorming, how do we share, how do we use this system more effectively so that it can benefit not only ourselves, but the group as a whole. That is how we managed to position CEMS as the system that we can use in our daily work not just a repository system.}

At the height of many disagreements between subsidiary managers and the $\mathrm{CXO}$, the alliance sensegive that CEMS's implementation was in disarray with many unresolved issues. They requested for a post mortem to be done. After several discussions, the CXO eventually conceded from the subsidiaries plea and agreed to perform a CEMS post implementation review (hereinafter PIR) to be led by M1. M1 recalled how he devised the PIR:

I did the assessment, I started from the very beginning, from the objective of the paper when we wanted to purchase the system. We selected the system, all the objectives set all the way to... So basically, it was more like the 'Post Implementation Review' looking

back and they were obviously a lot of issues raised and when we discussed about the opinions there was 'no official opinion' but you could gather there was double 'unsatisfactory'... of that line (M2).

The PIR identified seven major findings, namely i) poor project management, ii) nonutilisation of CEMS modules, iii) inadequate training provided, iv) unclear KPI achievement expectations, v) inconsistent usage of CEMS, vi) inadequate system administration and vii) unrealised project benefits. The CEMS PIR was presented by M1 at CenCo's divisional meeting attended by all key personnel from CenCo and MyCo. He explained:

[...] it was reported, and it was
presented, during the, what
you want to call it, the MyCo
leadership agenda during the
divisional team meeting. It was
presented during the Divisional
Meeting. So, everyone was there.
Everyone did not contest the
findings at all' (M1).

Post the CEMS PIR presentation, CenCo instructed M1 not to publish the report. M3 explained, 'I know what unofficially happened in KL but officially nothing is shared with us'. He summed up what transpired out of the exit meeting in the PIR CEMS meeting,

.. officially the report never
came out because the person who
reviewed the implementation, the
project that actually come out
with CEMS for the Group was
our own buddy we know actually
what happened behind the scene
(M3).




\section{Discussion}

This research explores a centre-led change initiative within the span of four years at CenCo. Relevant sensemaking (meaning to experience) and its related description of what manager's experience throughout the CEMS initiative development was compiled based on the 12 issues identified in Table 3.

\title{
Table 3
}

CEMS Key Issues - Centre and Subsidiary Sensegiving Activities

\author{
CEMS \\ Centre and subsidiary sensegiving activities \\ Key Issues
}

1. Funding of the system training

3. Subject matter expert
- The centre reiterated many times at the regional meetings that approval of central board had been obtained and that the subsidiary needs to comply.

- Many of the subsidiaries at the time were cash strapped. Their annual budget was regularly capped, especially for non-revenue generating projects.

- InCo was the only exception, their revenue accounts for $20 \%$ of CenCo's consolidated group revenue. Hence, they had the financial capability to fund a project such as CEMS.

- The centre emphasised that no cost to be incurred by the subsidiary, with no financial implication, thus it can just be used.

- The intention is good, but no understanding at subsidiary of how CEMS was to operate and what were its capabilities.

- CenCo sensegive that CEMS will improve the cycle time of performing work. CEMS will reduce the storage space of files and at the same time reduce use of paper (cost).

- CEMS shall be a part of the 3 years' pillar plans to increase automation and improve the work process at the subsidiary.

- CEMS shall be part of a broader "Go green project" (paperless) and at the same reduce workload of having to store work papers, thus reducing storage.

- Failure of the centre to manage the behavioural change of the end in mind (not about having a system). Users were not aware of what to expect of CEMS. What it is all about, the "what" and "how" to expect of the transition from paper-based to paperless work approach.

- The Centre did not handle or treat the CEMS transition as the paradigm shifts in how doing work and at par with MNE practices. The emphasis was more about driving the implementation and less about the soft skill part of it.

- The lack of expert within the group, CEMS requires a consistent push from the leadership team at the subsidiary. However, the centre was primarily concerned about the CEMS usage. Many of CEMS teething problems were either late or not addressed by the centre.

- Based on the PIR CEMS review, there were many CEMS capabilities that was not achieved. This was due to the centre's control of the functioning of CEMS.

- Subsidiaries had to put a tremendous level of effort to ensure CEMS is being used to an optimal level. This involved some reverse engineering by the users to come out workaround solutions. 
CEMS

Key Issues
Centre and subsidiary sensegiving activities
4. Data sovereignty

5. Accessibility

6. Data security

7. Complexity of process and procedure
- There is certain requirement set by regulators such as those in Indonesia that require information, e.g. Subscriber data must reside within the country. CEMS architecture for data centre is designed to reside centrally in Kuala Lumpur. This contradicts the special requirement at InCo.

- Several local discussions with the regulatory unit and local board member were engaged by InCo's manager.

- The introduction of the PDPA in many parts of the Asia region had led to the review of the subscriber database centre.

- Initially InCo was the only subsidiary allowed to implement an autonomous CEMS system. However, towards the tail end of this study, CenCO decided that CEMS was to be decentralised via the respective subsidiary budget.

- Users had to work off office hours during weekends or after KL working hours. There is 2-4-hour time difference between Kuala Lumpur (CenCo) and its subsidiaries.

- Checkout option in CEMS was used to allow usage without internet access. A template can be downloaded from CEMS and filled via a computer. Later, with an internet, the template can be uploaded into CEMS.

- 101-checklist was devised to allow new users to quickly learn how to use CEMS. The 101-checklist lists the minimum steps that are required to complete a report.

- Subsidiary although reluctant to commit too much resource for CEMS but they agreed that they need to support the Centre's CEMS initiative.

- CEMS is a web-based work system and the system with access via a tunneling technique known as a VPN.

- While the VPN is secure, the folder where the data being kept in CEMS was not fully secured. It is stored via a shared folder. Any authorised CEMS user with a basic IT knowledge will be able to access other users file and information.

- InCo installed a newer CEMS version that had resolved the data security issue which was still prevalent in the CenCo's version.

- The planning was excellent; however the implementation was haywire and too far from what the centre wanted to achieve. The implementation was underestimated, the level of complexity and know-how of the CEMS required a dedicated system administrator.

- Many users felt the complexity in using the CEMS both in terms of the application and the accessibility issues. There was no KPI set for the use of CEMS. They rationalise and consider the CEMS usage as optional or voluntary.

- Users were anticipating that ample time would be needed to get to use CEMS. Managers were not seen to be serious about CEMS' usage.

- Behavioural change in adopting CEMS (reward system) was needed to drive the CEMS usage. This had led to the introduction of specific KPI targets attached to report prepared via CEMS (timeliness and accuracy).

8. Lack of support

- The centre was very slow or not forthcoming at considering concerns/issues raised by the subsidiary. Many of the issues raised at the planning phase such as the CEMS' manual was not addressed.

- Other teething issues such as the timeouts and accessibility were also not resolved. Ironically, this was managed by the subsidiaries themselves. 
CEMS Key Issues

\author{
Centre and subsidiary sensegiving activities
}

9. Lack of direction - The project benefit analysis in the PIR CEMS report indicated that the CEMS project will benefit only the centre. There was very minimal amount of resource and work that was required to be committed by the centre as compared to the subsidiaries.

- CEMS is a dashboard reporting tool for the centre to monitor and manage from a centralised database.

- Subsidiaries felt that the CEMS is the Centre's project. It was not treated like a paradigm shift, i.e. New ways to do the work, as per what was shown during its introductory session in 2013.

- Amid the rebel alliance pact, the centre had to suppress CEMS PIR. Hence this had weakened the centre power. Subsidiaries were spared the constant pressure to increase usage of CEMS.

10. Rush through

- The Centre's approach move from directive rather than supportive, was described as "use or explain" approach by HQ. They were not concerned about issues, but rather the implementation and use of CEMS.

- CEMS was pushed through to be a permanent system and the primary agenda in major leadership meetings. Each subsidiary's CEMS implementation was displayed via statistical dashboard. Some described it as the "name and shame" session.

- The centre emphasised that in any established MNE, their system must be standardised. This is what CEMS is all about. It is a tool to ensure that the way of doing things is standardised across the CenCo group. The system too has to be strong enough to withstand personnel changes.

11. Objective not met

12. Differentiated treatment
- Users called the CEMS a "double work", "time waster" and "dumping data". It was an added burden (impossible to use CEMS real-time) it was merely a repository system. In reality, the users had to prepare reports manually and later load it into CEMS via its tedious steps and cumbersome processes.

- The CEMS usage statistics shown in regional meeting was more about displaying subsidiary performance tracking (name and shame). The centre was attempting to divert the attention from implementation, failure to subsidiary's lack of cooperation in using CEMS.

- Centre achieved its target to deploy CEMS across subsidiary and comply with the Standards. CenCo achieved the Level 5 KPI target in the centre, this is in contradiction with the CEMS project objectives as per the PIR CEMS report.

- CEMS was not used at MyCo after one year of implementation, it was up to subsidiary to proceed. Unlike $\mathrm{LaCo}$ and $\mathrm{BaCo}$, they were pressured by $\mathrm{CenCo}$ to increase the CEMS usage. InCo was spared as their access was off limits to CenCo.

- Unfair treatment of subsidiary e.g. MyCo lack usage, InCo dedicated resource. $\mathrm{BaCo}$ and $\mathrm{LaCo}$ were not able to employ dedicated resource to manage CEMS. CenCo monitors the ratio of resource to reports published, on a quarterly basis.
The authors matched various sensegiving activities to the distinctive key activity (12 CEMS issues) based on several layers of centresubsidiary, subsidiary and subsidiary-internal. Sensegiving activities such as the workaround solutions engaged at $\mathrm{BaCo}$ via the 101-checklist and working off office hours (KL Office) were related to the CEMS accessibility issue. Whereas the effort by M2 in Indonesia to garner support from its local board member and other internal parties were related to the data sovereignty issue. The three groups of sensegiving activities were analysed iteratively building a more abstract 
process descriptor. Within the multitude of sensegiving and sensemaking activities, next the authors deduced two patterns of interaction each for the two CEMS phases. In the planning/ implementation phase, a superficial/abstract pattern of interaction. Activities are described such as light conversation, low understanding and light discussion. Whereas at the BAU phase, an entrenched/specific pattern of interaction is described. Activities are described such as intense and confrontational discussion, and direct and one-on-one directives.
Finally, the authors identified commonalities in each account associated with each form and performing iterative analysis to build a more abstract description of the sensemaking form. What emerged from this (see Figure 2) is two sensemaking forms communication intensity and resolution to barriers. The communication intensity is described based on the direction of the arrow with specked lines indicate lower communication and thick lines indicate high communication between entities.

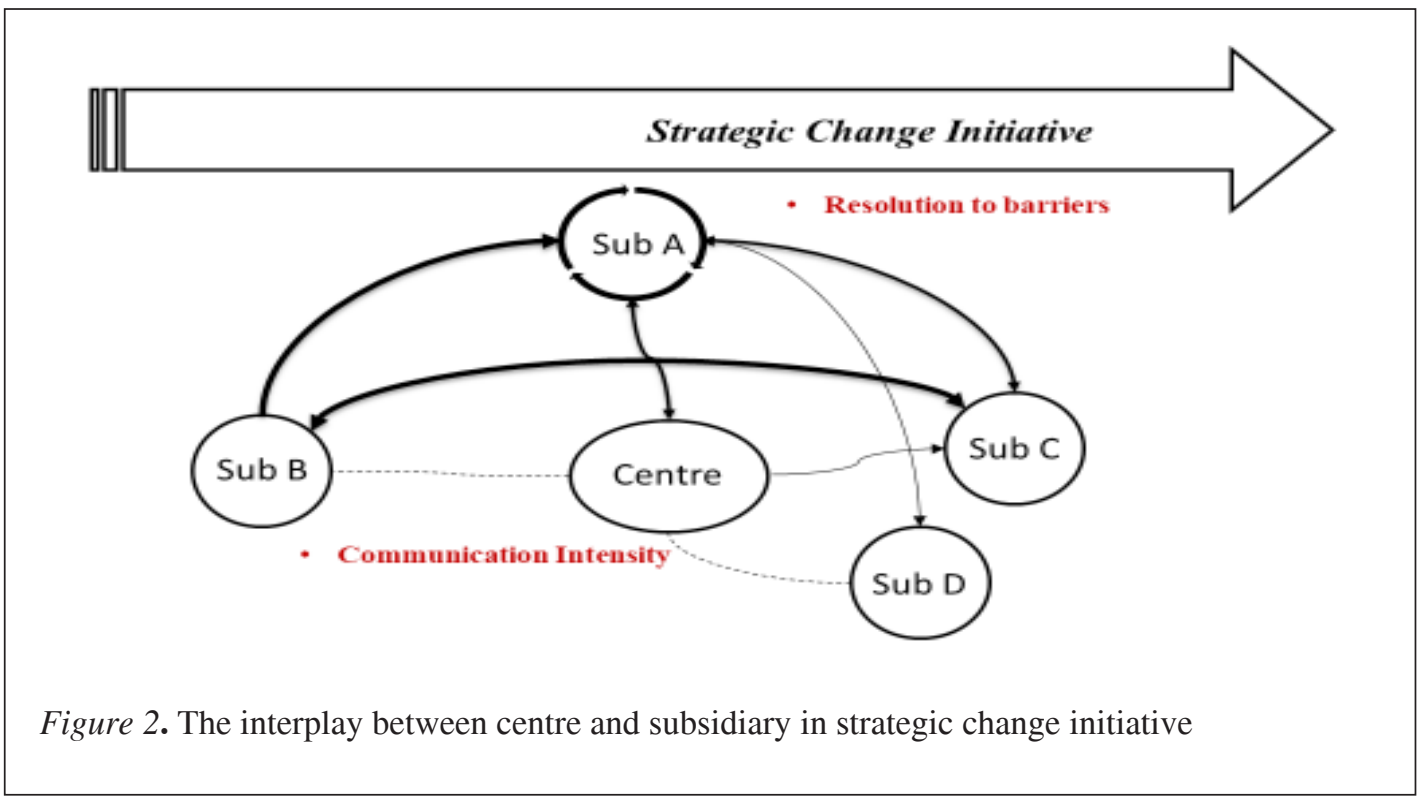

\section{Communication Intensity}

Communication intensity refers to the intensity of the enacted sensemaking and sensegiving between actors involved throughout the change development. Several layers of communication happening at the same time, namely: (1) the centre with subsidiary managers, (2) subsidiary managers with their internal teams and, (3) peer subsidiary managers. Communication intensity was clearly observed in the case of $\mathrm{BaCo}$, InCo and Laco. In some, the layers transcend down to the internal subsidiary itself. As for BaCo case, the teams were very active in several sensegiving activities among themselves, they devised several

workaround solutions. Teams were regularly discussing among themselves in suggesting new ways on how to make the CEMS to work. They opt to work on Sundays and off-office hours, use the 'checkout' function and follow the 101CEMS checklist.

Whereas LaCo and BaCo implemented CEMS via the centre-led initiative, InCo approach this differently. InCo from the beginning displayed 
a highly combative behaviour towards CenCo. Both were embroiled in intense, heated debate ranging from issues on the legality to several non-resolutions of CEMS problems. M2's persistent tactic backed the strength of InCo as a subsidiary, they managed to push through their agenda; build a standalone CEMS system (Dorrenbacher \& Geppert, 2009). In the rebel alliance, InCo was an active member, they provided insight about key information related to CEMS' flaws. This later had led the alliance to pressure CenCo to perform the post implementation review (PIR). Furthermore, InCo was instrumental in leading the pact to devise meticulous tactics such as lobbying for a PIR engagement in helping to steer the course of the change initiative. The reality is that many of CenCo's intended objectives were either derailed or transformed later.

\section{Resolution to Barriers}

Resolution to barriers refers to the efforts taken to overcome barriers to the change initiative. Anand and Barsoux (2017) defined barriers or blockers as vital components of change that need to be targeted when it happens. BaCo had recorded the highest number of accounts totalling 11 in their efforts to overcome the CEMS' related issues such as opting to increase their WIFI, speed and introducing a KPI for CEMS based on the 101-checklist. InCo was second with eight accounts of activities that included engaging their local board member and having a dedicated CEMS administrator. Both were consistently trying to find ways to overcome barriers and were quick to respond to change barriers at different levels, both internally and externally. CenCo, MyCo and LaCo recorded between 3-5 accounts of activities related to CEMS barrier resolution with LaCo being the highest among the three.

This study provides some new insights into the development of a centre-led change initiative in a multinational setting. The findings, however, should interpret in the light of certain limitations that suggest further possibilities for empirical research. The first limitation concerns the context of the study within the Asia region, which puts constraints to the generalisability of the findings in other parts of the world or in different industries. Other industry with stronger regulated regime involved in centreled change initiatives that may influence actors to act differently. Different nuance from these different settings may result in actors in deploying different tactics or strategies against or for the centre. Thus, it is envisioned that further studies be expanded in other different industries than limiting to telecom companies. The study also should be expanded to other parts of the world. The second limitation concerns the theoretical perspective that this study deploys. As the objective of this study is to understand why and how people do certain things the way they do. Perhaps future research should consider using other theoretical perspective in unravelling the different plots through layers of different discourses that may exist within employees, middle managers and senior managements (Hardy \& Maguire, 2010).

\section{Conclusion}

This study has explored a centre-led change initiative in understanding why individual and individuals do what they do. This was examined through the sensemaking lens. In the beginning, the centre manager assigned meaning to the CEMS initiative, they sensegive that it was about emulating an establish MNEs via office automation (Maitlis \& Lawrence, 2007).

Subsidiary managers as change recipients were at times in a state of confusion due to the imposed implementation by the centre (Guiette \& Vandenbempt, 2017, Lundgren-Henriksson \& Kock, 2016). Here, we see subsidiary managers attempt to make sense of the situation (Maitlis, 2005, Sonenshein, 2010) with their different set of individual view of the situation. Within this array of confusion, they had 
grouped together in what they call themselves as the 'rebel alliance' to overcome barriers set by the centre. Consistent with Giuliani's (2016) work on sensebreaking (Vlaar et al., 2008), it was found that during the change development, alliance members assign different meanings to change. The alliance, taking a more protagonist role (Maitlis \& Christianson, 2014), manage to steer the course of the CEMS change initiative.

In the end, the users' sensemake the CEMS as a system which they call "double work", "failure" and "repository system". This is in stark contrast to what the centre refers the CEMS as the way to go, emulating the established MNEs. However, in reality, it is about which narratives that survive that do matters. It is this one that will carry the meaning of change (Maitlis \& Lawrence, 2007).

The two patterns of sensemaking / sensegiving that emerged from this study offers centre managers a glimpse of how the development of change progresses over a period. The overall findings suggest that subsidiaries that manage to make significant progress implementing one or more centre-led initiatives were those that engaged in both sensemaking and sensegiving processes. It can be derived that, the most significant progress among the four subsidiaries were InCo and $\mathrm{BaCo}$. They were the early adopters of change, by being early in addressing difficulties and pressure (Higgins et al., 2014). They were able to shape the meaning of the initiatives.

The following points may highlight the expected development and outcomes of centreled change initiatives in-line with the findings of this study: (1) The centre needs to emphasise the behavioural aspect throughout the development stage of the change. This should help in ensuring a higher number of active adopters of change, (2) The centre needs to pay attention to any negative cues from subsidiaries, it has to be attended as quickly as possible, (3) The patterns identified may be a guiding principle for centres when delivering change initiatives. Even though it may not necessarily guarantee a successful implementation of the change initiative, a careful blend of the patterns identified may serve as a framework for the organisation to improve their success rate in implementing change (Burnes, 2011).

\section{References}

Anand, N., \& Barsoux, J.-L. (2017). What everyone gets wrong about change management. Harvard Business Review, 95(6), 79-85.

Asma, A. (1996). Going glocal : Cultural dimensions in Malaysian management. Kuala Lumpur: Malaysian Institute of Management.

Balogun, J. (2006). Managing change: Steering a course between intended strategies and unanticipated outcomes. Long Range Planning, 39(1), 29-49.

Balogun, J., Bartunek, J. M., \& Do, B. (2015). Senior managers' sensemaking and responses to strategic change. Organization Science, 26(4), 960-979.

Balogun, J., Jarzabkowski, P., \& Vaara, E. (2011). Selling, resistance and reconciliation: A critical discursive approach to subsidiary role evolution in MNEs. Journal of International Business Studies, 42, 765786.

Balogun, J., \& Johnson, G. (2004). Organizational restructuring and middle manager sensemaking. The Academy of Management Journal, 47(4), 523-549.

Balogun, J., \& Johnson, G. (2005). From intended strategies to unintended outcomes: the impact of change recipient sensemaking. Organization Studies, 26(11), 1573-1601.

Bartlett, C. A., \& Ghoshal, S. (1986). Tap your subsidiaries for global reach. Harvard Business Review, 64(6), 87-94.

Bartlett, C. A., \& Ghoshal, S. (2002). Managing across borders: The transnational 
solution (2nd ed.). Boston: Harvard Business School Press.

Belanger, J. (1999). Being local worldwide : ABB and the challenge of global management. Ithaca, N.Y. ; London: Cornell University Press.

Birkinshaw, J., Brannen, M. Y., \& Tung, R. (2011). From a distance and generalizable to up close and grounded: Reclaiming a place for qualitative methods in international business research. Journal of International Business Studies, 42(5), 573-581.

Birkinshaw, J., Hood, N., \& Young, S. (2005). Subsidiary entrepreneurship, internal and external competitive forces, and subsidiary performance. International Business Review, 14(2), 227-248.

Birkinshaw, J., \& Pedersen, T. (2009). The Oxford handbook of international business. In A. M. Rugman (Ed.), (2nd ed. ed.). Oxford: Oxford University Press.

Bouquet, C., \& Birkinshaw, J. (2008a). Managing power in the multinational corporation: How low-power actors gain influence. Journal of Management, 34(3), 477-508.

Bouquet, C., \& Birkinshaw, J. (2008b). Weight versus voice: How foreign subsidiaries gain attention from corporate headquarters. Academy of Management Journal, 51(3), 577-601.

Brandt, W. K., \& Hulbert, J. M. (1977). Headquarters guidance in marketing strategy in the multinational subsidiary. Journal of World Business, 12(4), 7-7.

Brown, A. D., \& Humphreys, M. (2003). Epic and tragic tales. The Journal of Applied Behavioral Science, 39(2), 121-144.

Burnes, B. (2011). Introduction: Why does change fail, and what can we do about it? Journal of Change Management, 11(4), 445-450.

Campbell, D. T., \& Stanley, J. C. (1963). Experimental and quasi-experimental designs for research. Handbook of research on teaching, 171-246.
Conroy, K. M., Collings, D. G., \& Clancy, J. (2017). Regional headquarter's dual agency role: Micro-political strategies of alignment and self-interest. British Journal of Management.

Creswell, J. W. (2009). Research design:

Qualitative, quantitative, and mixed methods approaches. London: Sage Publications.

Dohse, K., Jürgens, U., \& Nialsch, T. (1985). From "Fordism" to "Toyotism"? The social organization of the labor process in the Japanese automobile industry. Politics \& Society, 14(2), 115-146. doi:10.1177/003232928501400201

Dorrenbacher, C., \& Geppert, M. (2006). Micropolitics and conflicts in multinational corporations: Current debates, reframing, and contributions of this special issue. Journal of International Management, 12(3), 251-265.

Dorrenbacher, C., \& Geppert, M. (2009). A micro-political perspective on subsidiary initiative-taking: Evidence from Germanowned subsidiaries in France. European Management Journal, 27(2), 100-112.

Floyd, S. W., \& Wooldridge, B. (1992). Middle management involvement in strategy and its association with strategic type: A research note. Strategic Management Journal, 13(S1), 153-167. doi:doi:10.1002/smj.4250131012

Gephart, R. (1997). Hazardous measures: An interpretive textual analysis of quantitative sensemaking during crises. Journal of Organizational Behavior, 18(S1), 583-622.

Geppert, M., Becker-Ritterspach, F., \& Mudambi, R. (2016). Politics and Power in Multinational Companies: Integrating the international business and organization studies perspectives. Organization Studies, 37(9), 1209-1225.

Gioia, D. A., \& Chittipeddi, K. (1991). Sensemaking and sensegiving in strategic change initiation. Strategic Management Journal, 12(6), 433-448. 
Gioia, D. A., \& Thomas, J. B. (1996). Identity, image, and issue interpretation: Sensemaking during Strategic Change in Academia. Administrative Science Quarterly, 41(3), 370-403.

Giuliani, M. (2016). Sensemaking, sensegiving and sensebreaking The case of intellectual capital measurements. Journal of Intellectual Capital, 17(2), 218-237.

Guiette, A., \& Vandenbempt, K. (2017). Change managerialism and microprocesses of sensemaking during change implementation. Scandinavian Journal of Management, 33(2), 65-81.

Hardy, C., \& Maguire, S. (2010). Discourse, field-configuring events, and change in organizations and institutional fields: Narratives of DDT and the Stockholm convention. The Academy of Management Journal (AMJ), 53(6), 1365-1392.

Hedlund, G. (1980). The role of foreign subsidiaries in strategic decision-making in Swedish multinational corporations. Strategic Management Journal (pre1986), 1(1), 23-36.

Hedlund, G. (1986). The hypermodern MNCA heterarchy? Human Resource Management (1986-1998), 25(1), 9-35.

Higgins, C., Stubbs, W., \& Love, T. (2014). Walking the talk(s): Organisational narratives of integrated reporting. Accounting, Auditing \& Accountability Journal, 27(7), 1090.

Humphreys, M., \& Brown, A. D. (2002). Narratives of organizational identity and identification: A case study of hegemony and resistance. Organization Studies, 23(3), 421-447.

Isabella, L. A. (1990). Evolving interpretations as a change unfolds: How managers construe key organizational events. Academy of Management Journal, 33(1), 7-41.

Kanter, R. (1982). The middle manager as innovator. Harvard Business Review, $60(4)$.
Kvale, S., \& Brinkmann, S. (2009). InterViews : Learning the craft of qualitative research interviewing (2nd ed. ed.). Thousand Oaks ; London.: Sage Publications.

Lundgren-Henriksson, E.-L., \& Kock, S. (2016). Coopetition in a headwind - The interplay of sensemaking, sensegiving, and middle managerial emotional response in coopetitive strategic change development. Industrial Marketing Management, 58, 20-34.

Maitlis, S. (2005). The social processes of organizational sensemaking. The Academy of Management Journal, 48(1), 21-49.

Maitlis, S., \& Christianson, M. K. (2014). Sensemaking in organizations: Taking stock and moving forward. Academy of Management Annals, 8(1), 57-125.

Maitlis, S., \& Lawrence, T. B. (2007). Triggers and enablers of sensegiving in organizations. Academy of Management Journal, 50(1), 57-84.

Malnight, T. W. (1996). The transition from decentralized to network-based MNC structures: An evolutionary perspective. Journal of International Business Studies, 27(1), 43-65.

Miles, M. B., \& Huberman, A. M. (1994). Qualitative Data Analysis (2nd ed.). London: Sage.

Mudambi, R., Pedersen, T., \& Andersson, U. (2014). How subsidiaries gain power in multinational corporations. Journal of World Business, 49(1), 101-113.

Nohria, N., \& Ghoshal, S. (1997). The differentiated network: Organizing multinational corporations for value creation (1st Edition ed.). San Francisco: Jossey-Bass.

Ocasio, W., \& Joseph, J. (2008). Rise and Fall - or Transformation?: The Evolution of Strategic Planning at the General Electric Company, 1940-2006. Long Range Planning, 41(3), 248-272.

Reynolds, N.-S. (2015). Making sense of new technology during organisational change. New Technology, Work \& Employment, 30(2), 145-157. 
Rouleau, L., \& Balogun, J. (2011). Middle managers, strategic sensemaking, and discursive competence. Journal of Management Studies, 48(5), 953-983.

Rowley, C. (2017). Whither globalisation and convergence? Asian examples and future research. Asia Pacific Business Review, 23(1), 1-9.

Saunders, M., Lewis, P., \& Thornhill, A. (2009). Research methods for business students (5th ed.). Harlow: Pearson Education.

Sonenshein, S. (2010). We're Changing-or are we? Untangling the role of progressive, regressive, and stability narratives during strategic change implementation. The Academy of Management Journal (AMJ), 53(3), 477-512.

Teulier, R., \& Rouleau, L. (2013). Middle managers' sensemaking and interorganizational change initiation: Translation spaces and editing practices. Journal of Change Management, 13(3), 308-337.
Vlaar, P. W. L., Van Fenema, P. C., \& Tiwari, V. (2008). Cocreating understanding and value in distributed work: How members of onsite and offshore vendor teams give, make, demand, and break sense. MIS Quarterly: Management Information Systems, 32(2), 227-255.

Weick, K. E. (1995). Sensemaking in organizations: Sage Publications, Inc.

White, R. E., \& Poynter, T. A. (1984). Strategies for foreign-owned subsidiaries in Canada. Business Quarterly (pre-1986), 49(2), 59-69.

Yin, R. K. (2003). Case study research: Design and methods: Sage Publications.

Zander, U., \& Kogut, B. (1995). Knowledge and the speed of the transfer and imitation of organizational capabilities: An empirical test. Organization Science, 6(1), 76-92. 